\title{
PRESCRIÇÃO DIÅRIA DE ENFERMAGEM: CONDIÇÕES PARA A SUA IMPLANTAÇÃO COMO ATIVIDADE DE ROTINA DA ENFERMEIRA
}

\section{Maria Romana Friedlander *}

FRIEDLANDER, M.R. - Prescrição diária de enfermagem: condiçðes para sua implantação como atividade de rotina da enfermeira. Rev. Esc. Enf. USP, 7(2): 177-186, 1973.

Relato de uma experiência na qual procurou-se levantar e verificar as dificuldades e condiçōes necessárias para a implantaçāo da prescrição diária de enfermagem, como atribuição da enfermeira encarregada de uma unidade em um hospital geral, cujo campo é utilizado para ensino. Descrição das etapas que foram desenvolvidas e providências tomadas para a solução dos problemas que se iam verificando a cada passo da implantação.

\section{INTRODUÇÃO}

Em nossa atividade diária de docente, sentimos uma premente necessidade de encontrar, no campo de estágio de nossos estudantes, as melhores condiçðes possíveis para a realização do ensino clf́nico. Acreditamos também que, estando a prescrição diária de enfermagem introduzida como atividade de rotina da enfermeira, o material proveniente desta atividade poderia ser excelente meio para ensino clínico constante. Contudo, ainda é reduzido o número de hospitais que utilizam este sistema de trabalho de forma sistemática, o que dificulta qualquer experiência e ensino neste sentido.

Levada por estes motivos, resolvemos fazer uma experiência em uma unidade de enfermagem de um hospital geral, com cerca de $\mathbf{1 . 2 0 0}$

- Auxiliar de Ensino da disciplina Fundamentos de Enfermagem. 
leitos, na qual procuramos verificar as dificuldades que poderiam surgir, tentando implantar a prescrição de enfermagem como atividade diária e de rotina da enfermeira encarregada da unidade. A implantação foi concretizada e sistematizada por um mês.

Esta experiência foi extremamente válida no sentido de podermos visualizar, com certa clareza, o conjunto de dificuldades e condiçðes necessárias à introdução desta nova atividade na rotina da enfermeira. São estes, portanto, os aspectos que vamos tentar descrever neste trabalho, uina vez que a introdução de uma nova atividade em um hospital, já funcionando em outras condiçðes, necessita adaptaçðes e mostra caracterŕsticas próprias que poderão ser de certa utilidade em posteriores implantaçðes deste gênero.

A unidade de enfermagem foi escolhida por nós por apresentar condições que julgamos favoráveis à experiência, tais como: condiçōes de planta f́́sica, número de pacientes não superior a trinta, funcionários treinados e enfermeiras interessadas na experiência.

\section{DETERMINAÇÃO DAS ETAPAS DO PROCESSO DE ENFERMAGEM}

Ainda dentro de uma fase que consideramos prévia à experiência, decidimos que as etapas a serem seguidas para a efetivação da prescrição diária de enfermagem seriam as seguintes:

a) levantamento inicial de dados do paciente, utilizando um formulário cujo preenchimento deveria fazer parte da rotina de admissão do paciente à unidade;

b) prescrição diária de enfermagem, ou plano de cuidados diários, sob forma de lista vertical e numerada dos cuidados de enfermagem específicos que deveriam ser prestados nas vinte e quatro horas seguintes, por toda a equipe de enfermagem, baseado nos dados levantados; optamos por esta forma de planejamento por ser de fácil consulta, fácil elaboração, de ter possibilidade de se arquivar para pošteriores consultas e poder constar do prontuário do paciente;

c) evolução diária do paciente, com resumo diário do estado 
do paciente e suas alteraçðes; esta evolução, além de ser uma das bases para o planejamento dos cuidados, seria um meio de avaliarmos os resultados das prescriçбes anteriores.

\section{CONDIÇÕES ADMINISTRATIVAS QUE JULGAMOS NECESSÁRIAS}

A primeira condição, computada por nós como imprescindível à implantação desta nova rotina, era o interesse e a colaboração da chefia de enfermagem, uma vez que esta nova atividade deveria ser considerada na determinação das funçðes da enfermeira encarregada. Sem esta aceitação não haveria possibilidade de se dar continuidade à experiência. Após termos a certeza de que poderíamos contar com o apoio da chefia de enfermagem, foram estudados os itens seguintes, com a finalidade de preservar o bom funcionamento da unidade e a praticabilidade do plano:

a) o número de funcionários e categorias de pessoal que a unidade deveria dispor, constantemente. Usamos fórmulas correntemente utilizadas pela administração hospitalar para o cálculo do número de funcionários e a determinação das categorias de pessoal necessárias ao funcionamento da unidade. Contudo, considerando que a prescrição diária de enfermagem seria uma atividade acrescentada às atribuiçðes da enfermeira responsável pela unidade (calculada empiricamente em sete minutos para cada paciente), concluímos que a existência de uma secretária, devidamente treinada, seria uma condição necessária, a fim de que houvesse disponibilidade da enfermeira, que delegaria d̀quela tarefas de ordem burocrática;

b) as condiçðes referentes ao pessoal de enfermagem, solicitadas à chefia de enfermagem, pois esta implantação influiria em todas as categorias de pessoal e seria necessário não só uma aceitação e adaptação do funcionário, como também se fariam necessárias a participação e colaboração de cada elemento. Foram solicitadas as seguintes condiçðes:

- que o funcionário deveria ser mantido fixo na unidade por um período de tempo mínimo igual a seis meses;

- que nọ, fosse dada a possibilidade de trocar de funcionários quando os mesmos não se adaptassem ao sistema; 
Estas condiçð̋es eram necessárias, não só pelas razões expostas acima, como também por estarem os funcionários habituados com uma escala diária de trabalho tipo funcional, ou seja, cada funcionário era escalado para cumprir determinada atividade em todos os pacientes da unidade. Com a prescrição de enfermagem, julgamos impossível que cada funcionário estivesse a par das prescriçð̄es de todos os pacientes. Portanto, fazia-se necessário uma reestruturação da escala diária de trabalho passando a mesma a ser do tipo integral, ou seja, que cada funcionário realizasse todas as atividades pertinentes à sua categoria, em um grupo constante de pacientes. Esta modificação colocada em prática mostrou ótima aceitação pelos funcionários.

c) rotinas de serviço que deveriam ser introduzidas ou complementadas. Com a finalidade de facilitar as condiçzes de trabalho, foram feitas as seguintes alteraçôs:

- na rotina de admissão do paciente à unidade incluiu-se um formulário a ser preenchido para o primeiro levantamento de dados sobre o paciente (Anexo 1).

- foram introduzidas Normas de Orientação à Prescrição Diária de Enfermagem (Anexo 2).

Considerando que esta implantação era de caráter provisório, nå quisemos introduzir um novo impresso, pois redundaria em gasto inútil para a instituição. Usamos um impresso antigo e não utilizado que, no momento, servia plenamente ao nosso objetivo, ou seja, efetivação da prescrição diária de enfermagem.

\section{PREPARO DAS ENFERMEIRAS}

De toda a experiência, esta foi a etapa que trouxe maiores dificuldades e a que, em nossa opinião, $\hat{e}$ a de maior influência ná execução da prescrição diária de enfermagem. A enfermeira tem que estar constanter mente se aprimorando e seu interesse não pode decair, do contrário não será possivel garantir o sucesso de seu trabalho.

Para o preparo das enfermeiras seguimos o seguinte roteiro: 
- estudo individual de toda a bibliografia colhida e, após o mesmo, várias reuniðes para discussão;

- discussão das novas rotinas e suas modificaçð̃es;

- estudo pormenorizado, e em grupo, de um pacieite recémadmitido na unidade, compreendendo a análise dos dados colhidos, os problemas do paciente e a elaboração do plano assistencial para aquele paciente, tendo como base os recursos oferecidos pela unidade de enfermagem.

Sugerimos que, a este preparo das enfermeiras, fosse dada maior atenção sem se dar maior importância ao tempo gasto.

\section{IMPLANTAÇÃO PROPRIAMENTE DITA E SUGESTÕES PARA SUA CONTINUIDADE}

Foi determinado um plano de implantação que consistiu em iniciar a prescrição diária de enfermagem, como para todos os pacientes que iam sendo admitidos. Desta forma o número de pacientes que exigia prescrição diária ia aumentando de forma gradual. permitindo que as enfermeiras se fossem aperfeiçoando, os funcionários se adaptando e evitando problemas de aceitação por parte dos pacientes mais antigos.

Com o decorrer do tempo, ficou visível a necessidade de se dar continuidade a este sistema de trabalho e ao aperfeiçoamento das enfermeiras. Para tanto, sugerimos à chefia de enfermagem que possibilitasse condiçð̃es para que:

a) houvesse, semanalmente, oportunidade de um estudo de problemas de pacientes entre as enfermeiras da Unidade e a Supervisora de Educação em Serviço;

b) fossem mantidas as condiçðes estabelecidas quanto ao número de funcionários e permanência dos mesmos na unidade;

c) fossem convidadas outras enfermeiras, incluindo as da Faculdade de Enfermagem anexa, para participarem dos estudos semanais;

d) houvesse possibilidade de que a Supervisora de Educaçāo 
em Serviço se mantivesse em contacto diário com a referida Unidade e as prescriçðes dos pacientes;

e) procurasse a enfermeira responsável apresentar um relatorio peribdico sobre suas atividades neste campo.

\section{CONCLUSÕES}

A realização deste trabalho foi, para nós, uma valiosa experiência, pois mostrou-nos, por um lado, a possibilidade e exequibilidade do trabalho da enfermeira dentro de padroes técnico-cientificos, desde que os responsáveis pela organização dos serviços de enfermagem incluam esta rotina na determinação das atribuiçðes da enfermeira da unidade. Por outro lado, mostrou-nos as dificuldades com que deparamos quando introduzimos uma nova rotina.

Em nossa opinião, existem fatores chaves que determinam o sucesso ou insucesso na implantação deste sistema de trabalho: o apoio, a colaboração, o interesse das chefias de enfermagem e o preparo rigoroso, constante e sistemático das enfermeiras encarregadas das prescriçð̃es diárias. 


\section{ANEXO 1 \\ Formulário para Levantamento de Dados do Paciente de Enfermagem}

Clínica:

Leito:

Data:

Nome:

Idade:

Est. Civil:

Diagnóstico médico:

Sexo:

Grau Instr.:

Ocupação:

Religião:

CONDIÇÕES GERAIS

Estado de Higiene: (pele, unhas, dentes e cabelo):

Sinais Vitais:

Locomoção:

Estado Mental:

Estado de Nutrição:

HÁBITOS

Repouso:

Recreação e atividades:

Alimentação:

CONDIÇŐES ESPECÍFICAS

Sist. Digestivo:

Sist. Cardio-Resp.:

Eliminaçð̃es (intestinal, vesical e menstrual):

Órgãos dos sentidos:

Sist. Muscular:

Sist. Ósseo e Artic.:

CONDIÇÕES PSICOLÓGICAS

\section{INFORMAÇÕES DA FAMÍLIA E DE OUTROS PROFISSIONAIS}

\section{QUEIXAS DO PACIENTE}


ANEXO 2

NORMAS DE ORIENTAÇÃO Ȧ PRESCRIÇÃO DIÅRIA DE ENFERMAGEM

(P. D. E.)

1 - Para a P.D.E. deverá ser utilizado o impresso Relatório de Enfermagem Mod. 0041.

2 - A P.D.E. deverá ser feita diariamente pela enfermeira do plantão da Manhã e individualmente para cada paciente. Não havendo possibilidade de se prescrever para todos os pacientes da Unidade, pelo menos prescrever para os casos mais graves.

3 - A P.D.E. deverá ser feita após rápida evolução escrita do paciente onde deverão estar incluídas queixas mais graves e informaçð̋es que auxiliam o tratamento médico $e$ a assistência de enfermagem.

4 - A validade da P.D.E. será das 10 horas de um dia até às 10 horas do dia seguinte.

5 - Cabe à enfermeira da Tarde: 10 fazer a P.D.E. inicial quando da admissão do paciente à Unidade. Essa prescrição terá validade até às 10 horas do dia seguinte. 20 fazer, em casos excepcionais, as P.D.E. dos pacientes da Unidade quando houver impossibilidade por parte da enfermeira da Manhã. 30 modificar, acrescentar ou suspender cuidados prescritos de manhã, quando houver necessidade.

6 - A P.D.E. deve ser redigida em linguagem acessível a todos os funcionários e deve conter orientaçðes referentes a:

- Dieta, Alimentação e Hidratação

- Cuidados de higiene corporal e conforto do paciente

- Sono, Repouso e Restriçoes da Movimentação

- Atividades, Exercícios, Mudanças de decúbito, Massagens e Posiçðes.

- Recreação 
- Cuidados com medicação e tratamentos

- Encaminhamentos

- Controles: T.P.R. e PA, Diurese, Peso, Hídrico, ... etc..

- Cuidados com as necessidades psico-sociais do paciente.

- Cuidados com a comunicaçăo: estado de consciência, dos sentidos, contactuação com o mundo exterior, ... etc.. 
FRIEDLANDER, M.R. - Daily nursing prescription: conditions for its implementation as one of the nurse's routine activities. Rev. Esc. Enf. USP, 7(2): 177-186, 1973.

The objective of this experiment was to determine and verify the difficulties and necessary conditions for implemeting daily prescription as a responsability of a nurse in charge of a general hospital unit, used for traching purposes. Described herein are the various steps carried out and the measures taken in soluing the arising problems in each stage of mentioned implementation.

\section{BIBLIOGRAFIA CONSULTADA}

BITTENCOURT, Zaira; SANTOS, Aracy; MARQUES, Maria Helena O. Planejamento dos cuidados de enfermagem necessários a um paciente. Rev. Bras. Enf., 19 (2-3):64-76, abr./jun. 1966.

CARVAlHO, Anayde C. de - Plano de cuidados de enfermagem como uma das funçōes da enfermeira-chefe. Rev. Esc. Enf. USP, 2 (1):108-117, mar. 1968.

CIANCIARULlO, Tamara Ivanov; KOIZIMI, Maria Sumie; FERNANDES, Rosa Aurea Q. - Prescrição de enfermagem: experiências de sua aplicação em hospital particular. (Apresentado no XXV Congresso Brasileiro de Enfermagem, João Pessoa, 1973).

HORTA, Wanda de A. - A observação sistematizada como base para o diagnóstico de enfermagem. Rev. Bras. Enf., 24 (5): 46-53, jul/set 1971.

HORTA, Wanda de A. - A metodologia do processo de enfermagem. Rev. Bras. Enf., 24 (6):81-95, out./dez. 1971.

MORAES, Esther - Um plano de cuidados de enfermagem. Rev. Esc. Enf. USP, 1 (1):99-111, out. 1967.

OLIVEIRA, Clarice \& RIGAUD, Hyeda Maria - Plano de cuidado integral de enfermagem ao paciente hospitalizado. Rev. Bras. Enf., 21 (5): 458-470, out. 1968.

RAMOS, Neuza A. \& BALIELO, Vilma - O princípio da investigação e o processo de enfermagem sistematizada em enfermagem: uma experiência em Hospital de Clínicas. Rev. Bras. Enf., 24(5):53-66, jul./set. 1971. 